\title{
Comunidades tradicionais: a formação socio-histórica na Amazônia e o (não) lugar das comunidades ribeirinhas
}

\author{
Joyce Sampaio Neves Fernandes ${ }^{1}$ \\ https://orcid.org/0000-0002-4203-6859 \\ Liliane Moser ${ }^{2}$ \\ https://orcid.org/0000-0003-1601-9235 \\ ${ }^{1}$ Universidade Federal de Santa Catarina, Programa de Pós-Graduação em Serviço Social, Florianópolis, SC, Brasil \\ ${ }^{2}$ Universidade Federal de Santa Catarina, Departamento de Serviço Social, Programa de Pós-Graduação em Serviço \\ Social, Florianópolis, SC, Brasil
}

\section{Comunidades tradicionais: a formação socio-histórica na Amazônia e o (não) lugar das comunidades ribeirinhas}

Resumo: O objetivo deste artigo é analisar a formação socio-histórica da Amazônia, destacando o (não) lugar ocupado pelas comunidades ribeirinhas e por outros povos amazônicos, bem como problematizar o uso do território e a inserção da região amazônica no mundo globalizado. Trata-se de um ensaio teórico, com base em livros, revistas e artigos publicados, fundamentado em perspectiva crítica, e que busca evidenciar a trajetória socioeconômica e histórica da Amazônia marcada por uma intensa exploração dos seus recursos naturais visando atender aos interesses do capital. O plano de modernização da região culminou contraditoriamente no adensamento das expressões da questão social e marginalização dos povos amazônicos, em especial as comunidades ribeirinhas, historicamente excluídas nesse processo.

Palavras-chaves: Amazônia. Comunidades ribeirinhas. Formação socio-histórica. Território.

Traditional communities: socio-historical formation in the Amazon and the (non) place of riverside communities

Abstract: This article aims to analyze a socio-historical formation of the Amazon, emphasising the (non) place occupied by riverside communities and other Amazonian people, as well as to problematize the territory use and the amazon region insertion in the globalized world. It is a theoretical essay, according to books, magazines and published articles, based on a critical perspective. Regarding this socioeconomic and historical trajectory of the Amazon is marked by intense exploitation of its natural resources that aims to serve the capital interests. The modernization plan of the region culminated in a contradictory way in the densification of the social issue's expressions and marginalization of the amazonian people, especially as Riverside communities, historically excluded from this process.

Keywords: Amazon. Riverside communities. Socio-historical formation. Territory.

Recebido em 25.02.2021. Aprovado em 15.05.2021. Revisado em 12.07.2021.

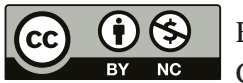

Este é um artigo publicado em acesso aberto (Open Access) sob a licença Creative Commons Attribution NonCommercial, que permite uso, distribuição e reprodução em qualquer meio, sem restrições desde que sem fins comerciais e que o trabalho original seja corretamente citado. 


\section{Introdução}

Sabe-se que a região amazônica possui um vasto território, rico em biodiversidade, fauna e flora. De acordo com Marques (2019), a Amazônia é o maior bioma brasileiro, não sendo fácil delimitá-la e nem identificar quais são as suas reais fronteiras por dois motivos: primeiro, porque ela ultrapassa as fronteiras do Brasil; segundo, porque as delimitações mudam de acordo com o critério utilizado (floresta, clima, relevo ou bacia hidrográfica). Além da extensão territorial e de suas riquezas naturais, a região amazônica apresenta uma pluralidade étnico-cultural (quilombolas, indígenas, ribeirinhos, caboclos, seringueiros, entre outros) advinda do processo de colonização e miscigenação. Dentre esses grupos sociais, destacam-se, para o contexto do presente estudo, as comunidades ribeirinhas.

Os ribeirinhos residem às margens dos rios, vivendo, especialmente, da caça, pesca e do extrativismo vegetal. O manejo das áreas de várzea, as técnicas produtivas e de organização social são conhecimentos herdados dos indígenas que viviam nessas áreas no período pré-colonial. A territorialidade ribeirinha se estabelece, principalmente, a partir do rio. $\mathrm{O}$ ambiente das águas tem muita influência na vida ribeirinha, seja na construção das casas, na escolha do horário para as práticas da pesca, entre outras. Por isso, o rio possui um alto poder simbólico e de representatividade.

O objetivo deste artigo é analisar a trajetória socio-histórica da Amazônia, destacando o (não) lugar ocupado pelas comunidades ribeirinhas, bem como os povos amazônicos de modo geral, problematizando o uso do território e a inserção da região amazônica no mundo globalizado.

O caminho metodológico, com base em livros, revistas e artigos publicados, utilizou como palavraschave de busca os termos: comunidades tradicionais, ribeirinhos, território e Amazônia; considerando a revisão bibliográfica para elaboração da dissertação no período de janeiro de 2019 a agosto de 2020.

O artigo está dividido em quatro itens: no primeiro, será apresentada a compreensão dos termos comunidades tradicionais e ribeirinhos; o segundo refletirá sobre a invisibilidade das comunidades ribeirinhas na trajetória socio-histórica da Amazônia; no terceiro, será discutida a categoria território e problematizada a inserção da Amazônia no mundo globalizado; e, nas considerações finais, será exposto um apanhado geral das discussões tecidas.

\section{Comunidades tradicionais e ribeirinhos: considerações conceituais}

O termo comunidade tradicional é bastante utilizado na literatura, principalmente, referindo-se às populações ribeirinhas, pois é uma expressão que, geralmente, está associada ao espaço físico. Há, no âmbito das ciências sociais, um amplo debate teórico sobre o conceito de comunidade. Dentre os autores clássicos, Wagley (1957) foi um dos pioneiros a utilizar o termo comunidade tradicional para se reportar às sociedades amazônicas. A esse respeito, diz o seguinte:

Nas comunidades existem relações humanas de indivíduo para indivíduo, e nelas, todos os dias, as pessoas estão sujeitas aos preceitos de sua cultura. É nas suas comunidades que os habitantes de uma região ganham a vida, educam os filhos, levam uma vida familiar, agrupam-se em associações, adoram seus deuses, têm suas superstições e seus tabus e são movidos pelos valores e incentivos de suas determinadas culturas. Na comunidade, a economia, a religião, a política e outros aspectos de uma cultura parecem interligados e formam parte de um sistema geral de cultura, tal como o são na realidade (WAGLEY, 1957, p. 43-44).

Em sua pesquisa na Amazônia, Wagley (1957) identificou as peculiaridades da vida cotidiana do grupo social sobre o qual pesquisou, a infraestrutura (moradias, técnicas agrícolas, meios de transporte, entre outros) e a identidade sociocultural (relação homem-natureza, os conhecimentos transmitidos entre as gerações etc.).

Já Diegues (2008), numa perspectiva marxista, define comunidades tradicionais como aquelas cuja organização social e econômica apresenta pouca acumulação de capital, onde a força de trabalho assalariada não é utilizada. São comunidades nas quais os produtores independentes estão envolvidos em atividades econômicas de pequena escala, como a agricultura, pesca, coleta e artesanato, ou seja, baseiam-se economicamente no uso de recursos naturais renováveis. Nessa vertente, Barroso (2015) diz que há uma relação de dependência entre as 
sociedades tradicionais e o meio urbano no âmbito da reprodução social, econômica, cultural e política, ademais, é do meio urbano que provêm as inovações que contribuem para a gradual transformação dessas sociedades.

Chaves (2001), em seus estudos, também utiliza o termo comunidade. Essa expressão pode ser compreendida no contexto social, cultural, político e econômico. Segundo o autor, "[...] a comunidade é composta por um conjunto de relações/intercâmbios de produção e político-organizativa dos homens entre si e com a natureza" (CHAVES, 2001, p. 78). Além disso, afirma que a relação sociedade-natureza não é harmoniosa e invariável, é conflituosa e, portanto, dialética, podendo esses intercâmbios ocorrerem de formas diferenciadas em cada contexto comunitário.

Dessa forma, em consonância com a perspectiva crítica que orienta este artigo, utiliza-se aqui o termo comunidades tradicionais. Apesar do reconhecimento da ambiguidade presente na expressão tradicional, ela será aqui utilizada por carregar elementos de ancestralidade ligados a saberes que envolvem a relação homem-natureza e a territorialidade, envolvendo, por conseguinte, a produção-reprodução social e cultural, bem como a identidade desses povos.

A Amazônia brasileira é composta por uma variedade de povos e etnias oriundos da miscigenação, fruto do processo de colonização e ocupação que sobreveio à região. Arenz (2000) afirma que essa miscigenação foi decretada pelo Estado português. A população ribeirinha, de origem ameríndia, chamada de cabocla, foi então moldada através dos aldeamentos dos missionários e nas vilas dos colonos, do século XVII ao XIX.

No tocante às populações ribeirinhas, há, na literatura, variedades de denominações para se referir a esses grupos e ao seu modo de vida. Chaves e Furtado (2017) utilizam o termo povos das águas; já as autoras Furtado e Maneschy (2002) utilizam a expressão ribeirinidade, sendo as pioneiras nessa dominação. Magalhães e Cunha (2017) fazem referência ao modo de vida ribeirinho, que no Xingu, é denominado de beiradeiros, ou seja, aqueles que vivem no beiradão. Fraxe (2004), por sua vez, utiliza a categoria ilhéus, com o intuito de ressaltar a identidade dos caboclos-ribeirinhos moradores da Ilha do Careiro da Várzea, no estado do Amazonas.

Tendo isso posto, pode-se afirmar que a expressão ribeirinho não apresenta uma única definição. E, apesar dos diversos termos existentes que se referem a esses grupos, todos os autores mencionados concordam que os ribeirinhos são aqueles que, além de residirem às margens de ambientes aquáticos, possuem relações simbólicas, culturais, sociais com esse espaço natural. Neste artigo, utilizar-se-á o entendimento de Neto e Furtado (2015, p. 160):

O termo ribeirinho, contudo, busca identificar um perfil sociocultural de grupos caboclos que se estabeleceram às margens dos rios, num espaço dinâmico que articula as relações de sociabilidade e culturais dentro das particularidades desse espaço, onde a marca dessa configuração pode ser vista nos comportamentos, na maneira de viver, em sua alimentação, nas crenças, em sua religiosidade etc., específicos daquele espaço.

Pois, nessa concepção, a expressão ribeirinho carrega uma identidade sociocultural. Aliás, será utilizado o termo comunidades ribeirinhas, em consonância com a expressão anteriormente problematizada.

Em relação à cultura, técnicas agrícolas e artesanais, Chaves (2001) afirma que as populações ribeirinhas herdaram tais conhecimentos dos indígenas que viviam nas várzeas, sendo eles: a confecção das redes, o preparo da farinha, a coleta de frutos, óleos, resinas silvestres e materiais para habitação (palha, tábuas), as técnicas de caça e pesca e a extração de matérias-primas para confeccionar peças artesanais e utensílios domésticos.

No que tange à estrutura de suas residências, Neto e Furtado (2015) afirmam que a maioria delas é construída com madeira e palha, e se elevam sobre estacas (palafitas) para ficarem a salvo das inundações periódicas.

Pojo et al. (2014) afirmam que a relação cotidiana estabelecida entre os ribeirinhos e as águas evidenciam que os rios são territórios (lugar, espaço e tempo). Portanto "[...] é o fluxo e o tempo-espaço das águas que dirigem a vida ribeirinha" (POJO et al., 2014, p. 183). Além disso, esses autores também afirmam que a afinidade e interação com o rio contribuem na formação da identidade nativa. Tal dinâmica se constitui no movimento da vida através das suas primeiras experiências na infância: banhos no rio, aprender a remar e a se equilibrar no trapiche de suas casas etc. No entanto, Fraxe (2004) afirma que essa relação construída entre os ribeirinhos e os rios consiste em uma interrelação construída historicamente, não sendo, portanto, algo dado.

De acordo com Noda et al. (2001), a pesca possui uma forte representatividade nos aspectos socioculturais. Os ribeirinhos se apropriaram dessa atividade, que, inicialmente, foi desenvolvida pelos indígenas. No entanto, 
aprimoraram seus utensílios, adequando-os às suas necessidades, como, por exemplo, o arco e flecha, a zagaia e arpão (haste) e a malhadeira. A prática da pesca ribeirinha, segundo Lira e Chaves (2016), é uma atividade predominante e intensa dessas comunidades, sendo executada nos lagos, igapós, igarapés e rios, cujos meios de transporte são, normalmente, a canoa movida a remo e/ou motor de rabeta.

Tais práticas produtivas são guiadas através da relação homem-natureza, ou seja, através das múltiplas relações estabelecidas com o ambiente natural somadas aos conhecimentos acumulados de geração em geração. $\mathrm{O}$ ribeirinho desenvolve suas atividades produtivas baseando-se nos ciclos naturais, como, por exemplo, a reprodução e migração da fauna, a influência da Lua nas atividades de corte da madeira, da pesca e do roçado, os sistemas de manejo dos recursos naturais, entre outros.

Essas atividades produtivas estão pautadas em relações de respeito com a natureza e manutenção da subsistência de seus grupos, não em função das relações de produção para atender às demandas do mercado (LIRA; CHAVES, 2016). Entretanto, em algumas comunidades mais próximas das grandes cidades, a pesca, além de contribuir para a subsistência de suas famílias, também é fonte de renda, e o pescado é, portanto, comercializado no centro da cidade ou na própria comunidade pelos famosos marreteiros (POJO et al., 2016).

Além de problematizar definições e o modo de vida dos ribeirinhos, faz-se necessário também conhecer o lugar dessas comunidades no processo socio-histórico da Amazônia, conteúdo que será abordado a seguir.

\section{O (não) lugar das comunidades ribeirinhas na trajetória socio-histórica da Amazônia}

Na era pré-colonial, segundo Arenz (2000), existiam indígenas amazônicos que viviam na várzea e apresentavam uma complexidade sociocultural, a qual foi destruída através do projeto civilizatório-cristão com a chegada dos europeus à região. Entretanto, houve resistência à servidão, bem como à colonização, através de fugas e revoltas que resultaram em uma completa marginalização social e total negação de identidade étnica e cultural.

Mesmo marginalizados, os ribeirinhos conseguiram resistir a uma colonização total, preservando os principais eixos da cultura de seus antepassados: aspectos econômicos (integração à natureza, extrativismo vegetal), sociais (vivência autônoma em pequenas comunidades) e religiosos (prática da pajelança como expressão de sua cosmovisão própria). Ainda, consideram que "a língua portuguesa e a religião católica são 'pontes' para o mundo dos 'brancos', mas não determinaram e nem expressam, por completo, a autonomia social e cultural dos ribeirinhos" (ARENZ, 2000, p. 12).

O período da produção da borracha, entre 1850 e 1920, representou um momento de grande riqueza para a região, na qual destacam-se as cidades de Belém e Manaus (SÁ; NASCIMENTO, 2012). A Amazônia, através da extração do látex (matéria-prima para produção da borracha), foi então integrada às relações comerciais internacionais. Nesse período, houve um intenso processo de migração, principalmente de nordestinos para a região, através de incentivos governamentais, a fim de trabalharem nos seringais.

As condições de trabalho eram degradantes e de intensa exploração do seringalista (donos ou arrendatários das áreas de extração da seringa) para com o seringueiro (coletores da borracha, em sua maioria nordestinos).

A produção da borracha sustentava-se por meio do sistema de aviamento. Segundo Gomes (2012), tal sistema consistia em um intercâmbio comercial, em que bancos e casas exportadoras europeias e norteamericanas disponibilizavam capitais para as casas aviadoras localizadas em Belém e Manaus, que incentivavam os seringalistas a criarem postos comerciais ou mesmo barracões administrados por pequenos comerciantes.

Tal intercâmbio comercial localizava-se ao longo das vias fluviais. Desse modo, os aviadores adiantavam alimentos ou ofereciam empréstimos aos seringueiros para que pudessem comprar os utensílios necessários para a extração da borracha, em troca, eles eram obrigados a entregar toda a sua produção.

Dessa forma, as novas relações sociais estabelecidas no período da borracha contribuíram para a marginalização do ribeirinho, que "passou a ser considerado um mero morador da beira do rio e um remanescente do projeto mercantilista ultrapassado" (ARENZ, 2000, p. 56). Além disso, nessa época, emergiram várias pesquisas comparando o ribeirinho amazônico ao imigrante nordestino, reforçando a exclusão econômica e social da população ribeirinha, já que consideravam os ribeirinhos como inertes e inviáveis para as exigências de uma economia capitalista moderna. 
A ascensão da produção da borracha abriu novas áreas de povoamento: "em todas as bocas de igarapés e de rios com recursos e possibilidades de exploração, localizava-se um posto ou comércio que tinha a função de canalizar a produção agroextrativista trazida das terras interiores e de drená-la para os portos e cidades maiores." (CASTRO, 2008, p. 17-18). E, justamente, pelo fato de o sistema de aviamento se dar por via fluvial, a comercialização e troca de mercadorias nos cursos d'água contribuíram para o povoamento às margens dos rios e seus vales. Esse processo consistiu no primeiro padrão de ocupação e expansão urbana na Amazônia (CASTRO, 2008).

Entre 1910 e 1940, a exportação da borracha entrou em declínio "em função da concorrência inglesa nas colônias asiáticas, fruto do contrabando da semente havea brasiliensis" (SÁ; NASCIMENTO, 2012, p. 206, grifo do autor), provocando uma consequente estagnação na economia. Com a queda dos preços no mercado internacional, os centros comerciais e os barracões localizados nas vias fluviais foram fechados, havendo uma significativa migração de trabalhadores para os centros urbanos. Além de provocar um crescimento desordenado das cidades, com a precariedade dos serviços básicos e a falta de oferta de emprego, intensificouse a degradação das condições de vida desses trabalhadores.

Nos dizeres de Castro (2008), o segundo padrão de ocupação e povoamento na Amazônia ocorreu a partir da década de 1960, mais precisamente a partir de 1966, com maior intensidade nas décadas de 1970 e 1980, período em que ocorreu um avanço da fronteira agrícola através de programas governamentais.

A Amazônia, no período de ditadura militar, foi considerada um imenso espaço vazio que precisava ser ocupado. Através do discurso midiático "terra sem homens, para homens sem terras" o governo militar buscava atrair empreendedores e imigrantes de várias regiões do país. Nesse momento, a região vivenciou a chamada Operação Amazônia, através de mudanças nos estatutos legais (Estatuto da Terra, em 1964; Revisão do Código de Minas, em 1967; Política de Incentivos Fiscais, em 1966, entre outros) com o intuito de atrair investidores nacionais e estrangeiros para a região (SÁ; NASCIMENTO, 2012).

Outra medida adotada pelos militares, na década de 1970, foi a construção de estradas e rodovias, cuja finalidade era integrar a Amazônia às demais regiões do país, "além da Transamazônica (BR 230), das estradas Perimetral Norte (BR 210), Santarém-Cuiabá (BR 163) e Manaus-Porto Velho (BR 319), que se somariam à rodovia Belém-Brasília (BR 010), construída no governo de Kubitscheck" (SÁ; NASCIMENTO, 2012, p. 210).

Segundo Arenz (2000), essa política de povoamento teve por estratégia a formação de núcleos de aparência e infraestrutura urbana na beira das rodovias recém-abertas, com o intuito de facilitar o acesso aos colonos e também como atrativo para os imigrantes. Ademais, o autor afirma que houve um crescimento da população urbana, o qual atingiu não somente os núcleos recém-criados, como também as velhas cidades na beira dos rios, aumentando, assim, o índice de mão de obra excluída do processo de produção. Tais transformações socioeconômicas também impactaram as populações tradicionais, em especial as comunidades ribeirinhas, "pois o isolamento vivido anteriormente por eles não forneceu uma base para reagir ante a expansão agressiva de empresas e projetos dos 'novos grupos econômicos'" (ARENZ, 2000, p. 69).

Dessa forma, observa-se que o imigrante e os povos tradicionais - no caso, as comunidades ribeirinhas — não foram integrados como coprotagonistas nesse processo de ocupação da Amazônia na década de 1960, mas sim mantidos a distância, como uma massa de mão-de-obra informal, flexível e disponível quando necessária. Apesar de terem conseguido preservar a agricultura e o extrativismo vegetal de subsistência, o impacto sociocultural para as populações locais foi desastroso comparado aos avanços econômicos pretendidos com o desenvolvimento da Amazônia (ARENZ, 2000).

Ainda no período da ditadura, mais precisamente na década de 1980, o capital estrangeiro adentrou a região com maior intensidade. A partir da revisão do Código de Minas foi possível realizar um levantamento das áreas que apresentavam recursos naturais, mapeamento realizado através do Projeto Radar da Amazônia (RADAM). A região tornou-se novamente polo atrativo de investimentos e contribuiu para a implantação de empreendimentos industriais, os chamados grandes projetos. Sá e Nascimento (2012), em consonância com Magalhães Filho (1987), afirmam que o termo mais apropriado seria grandes intervenções, ao invés de grandes projetos, e os classificou em dois eixos: 1) grandes projetos de desenvolvimento regional explícito e 2) grandes projetos setoriais/nacionais.

No primeiro eixo - grandes projetos de desenvolvimento regional explícito — destacam-se os incentivos fiscais administrados pela Superintendência de Desenvolvimento da Amazônia (SUDAM) (apoio a projetos do setor privado); os incentivos fiscais administrados pela Superintendência da Zona Franca de Manaus - 
SUFRAMA (também com apoio a projetos do setor privado); o programa de polos agropecuários e agrominerais da Amazônia (POLAMAZÔNIA); o programa de desenvolvimento do Centro-Oeste (POLONOROESTE); e, por fim, o Projeto de Desenvolvimento Rural Integrado do Amazonas (PDRI Amazonas). No segundo eixo — grandes projetos setoriais/nacionais - destacam-se o programa grande Carajás (Carajás - Ferro; Albrás/ Alunorte - Alumina e Alumínio); a Hidroelétrica de Tucuruí; a Estrada de Ferro Carajás (EFC) ligando Parauapebas/PA a São Luís/MA; o Porto da Vila do Conde em Barcarena/PA; o projeto Jari; o Programa da Borracha (PROBOR); e, finalmente, o projeto Trombetas - mineração de bauxita (SÁ; NASCIMENTO, 2012).

De acordo com Arenz (2000), nessa última fase histórica amazônica, novos conflitos foram desencadeados, pois não se tratava da ocupação de lotes de terra, mas de territórios inteiros, como, por exemplo, Grande Carajás no sul do Pará. Tais conflitos permanecem fortemente presentes na região, e as comunidades ribeirinhas, bem como as populações tradicionais de modo geral, continuam marginalizadas e excluídas. Pode-se citar como exemplo de conflitos da atualidade a expulsão dos ribeirinhos do Rio Xingu, no município de Altamira no estado do Pará, para a construção da Usina Hidrelétrica de Belo Monte (MAGALHÃES; CUNHA, 2017).

Além disso, Arenz (2000) aponta um novo desafio para a região amazônica, a biotecnologia, que de um lado visa à preservação da natureza, e de outro sua exploração. Segundo o autor, as plantas naturais da Amazônia tornaram-se uma matéria-prima de suma importância para a indústria farmacêutica nos últimos anos. Sabe-se também que pesquisadores e empresas estrangeiras têm explorado os saberes das comunidades indígenas, sem respeitar os direitos autorais. Tais atos criminosos são denominados biopirataria.

Todavia, as transformações que resultarão dessa nova frente ainda não podem ser previstas, mesmo que haja um forte apelo, não somente para a preservação ecológica, "mas de uma conservação dinâmica que segura o potencial natural e o coloca à disposição do usufruto responsável das populações, em primeiro lugar as da região e, depois, as fora dela" (ARENZ, 2000, p. 71).

Diante disso, é notório o movimento de marginalização das comunidades tradicionais, em especial das ribeirinhas, no caminhar do desenvolvimento da Amazônia, bem como a ausência do Estado e a carência de políticas públicas voltadas para esses grupos sociais. Além disso, a região tem sido marcada por intensa exploração dos seus recursos naturais, inclusive de formas ilícitas, para fins lucrativos, riqueza essa que não é socialmente distribuída, adensando as desigualdades sociais e os conflitos socioambientais (FERNANDES, 2020).

\section{Uso do território: problematizando a particularidade amazônica no mundo globalizado}

No que tange à região amazônica, o entendimento da categoria território é de suma importância, pois trata-se de uma região que possui um território vasto, diverso e complexo, abrigando diferentes grupos sociais (indígenas, quilombolas, ribeirinhos, seringueiros, pescadores, entre outros). No entanto, o território que será abordado brevemente neste item é o território usado, conceito basilar que compõe os estudos do geógrafo brasileiro Milton Santos.

Segundo Santos (2007), o território não consiste apenas em um conjunto dos sistemas naturais e de sistemas de coisas superpostas, mas deve ser entendido como território usado, sendo que é o uso do território, e não o território em si, que faz dele objeto de análise social (SANTOS, 2005; 2007). Para o autor, o território usado seria o chão e mais a identidade, ou seja, o sentimento de pertencimento, de pertencer àquilo que nos pertence. Portanto, "o território são formas, mas o território usado são objetos e ações, sinônimo de espaço humano, espaço habitado" (SANTOS, 2005, p. 255). "[...] O território é o fundamento do trabalho; o lugar da resistência, das trocas materiais e espirituais e do exercício da vida" (SANTOS, 2007, p. 14).

Sinônimo de espaço geográfico, o uso do território se dá pela dinâmica dos lugares. De acordo com Santos e Silveira (2006), ele pode ser definido pela implantação de infraestruturas, denominadas pelos autores como sistemas de engenharia, mas também pelo dinamismo da economia e da sociedade. Nesse sentido, Santos e Silveira (2006) afirmam que o espaço geográfico é sempre histórico, e sua historicidade deriva da junção entre as características da materialidade territorial e as características das ações. Portanto, quando quisermos definir qualquer pedaço do território, deve-se levar em consideração a interdependência e a inseparabilidade entre a materialidade, que inclui a natureza, e o seu uso, que inclui a ação humana, isto é, o trabalho e a política. 
Considerando a perspectiva do território usado, cabe aqui refletir sobre o uso do território amazônico no contexto do mundo globalizado. Para Santos (2001), a globalização é, de certa forma, o apogeu do processo de internacionalização do mundo capitalista. A nova ordem mundial, denominada por ele como globalização perversa, é sustentada por uma ideologia dominante que supervaloriza o mercado e estimula o consumo, a competitividade e a individualidade, em detrimento da solidariedade e moralidade. "Um mercado avassalador dito global é apresentado como capaz de homogeneizar o planeta quando, na verdade, as diferenças locais são aprofundadas" (SANTOS, 2001, p. 19).

A respeito da região amazônica, Hurtienne (2009) afirma que a Amazônia sempre foi considerada pela sociedade global como uma das últimas fronteiras de exploração dos recursos na expansão da economia mundial, um espaço econômico para a acumulação do capital nacional e internacional. E do ponto de vista ecológico, é considerada como uma das últimas reservas biológicas, um imenso depósito, estabilizador do clima, um patrimônio da sociedade global que precisa ser cuidado.

Essas duas dimensões que compõem esse discurso, a econômica e a ecológica, são opostas e contraditórias, visto que o modelo dominante de globalização está baseado na exploração dos recursos não renováveis e dificilmente recicláveis. A expansão do capitalismo, na região, tem causado profundos danos ambientais, resultado de um extrativismo predatório, que é diferente do extrativismo dos povos indígenas ou dos caboclos, que geralmente é sustentável (HURTIENNE, 2009). Além disso, essa compreensão unilateral reforça a ideia de atraso da região amazônica e, por isso, a necessidade de modernizá-la, o que invisibiliza as comunidades tradicionais (ribeirinhos, indígenas, quilombolas e demais povos amazônicos) que ocupam o território, mascarando as expressões da questão social e os conflitos historicamente existentes.

Sobre a modernização, é importante ressaltar que a ação do Estado é efetiva nesse processo. Segundo Mascaro (2013), o Estado se revela como um aparato necessário à reprodução capitalista, à medida que, através das suas ações, assegura a troca das mercadorias e a própria exploração da força de trabalho sob forma assalariada.

No caso da região amazônica, as estratégias governamentais foram incisivas, visando atender os interesses do capital externo, principalmente nas décadas de 1960 e 1970, através de investimentos em infraestrutura, telecomunicações, transportes, construção de portos, rodovias etc. E essa modernização das cidades, sobretudo das cidades amazônicas, é paradoxal e contraditória, pois de um lado identifica-se a adesão e integração aos circuitos da alta tecnologia, e de outro o crescimento da desigualdade, segregação e marginalidade (CASTRO; SANTOS, 2006).

Iamamoto (2009), ao se referir às consequências dessa modernidade na sociedade brasileira, afirma que ela tem reforçado traços históricos persistentes em nossa formação social, é o moderno sendo construído por meio do arcaico e, ao mesmo tempo, transformando-o no contexto da globalização, adensando a questão social no País.

No tocante às cidades amazônicas, essa afirmação é bastante pertinente, heranças do passado se fazem presentes no cotidiano da região. Castro e Santos (2006) trazem como exemplo o sistema portuário da cidade de Belém, capital do estado do Pará. A reestruturação dos portos, na atualidade, está facilitando a circulação de mercadorias originárias do processo de produção extrativista (minérios, madeira, pescado, entre outros), mantendo, portanto, as mesmas práticas econômicas de exportação de matéria-prima que predominaram no período da colonização. Ou seja, mesmo com a presença de grandes estruturas empresariais, o perfil extrativista se mantém como base da economia na Amazônia.

Tendo em vista a complexidade do território amazônico e a pluralidade étnico-cultural, cabe ainda a reflexão acerca das políticas públicas destinadas à região. Segundo Teixeira (2013), pensar as políticas públicas para a Amazônia, bem como consolidá-las, é desafiador, pois a particularidade regional requer especificidades na leitura da questão social em seu território. Ademais, Teixeira (2008) afirma que as políticas públicas destinadas à Amazônia continuam revelando uma padronização que homogeneíza a realidade brasileira nos moldes das referências sul/sudeste, onde as práticas de uma única cultura impõem-se como referência no planejamento dos ministérios, engessando a autonomia de estados e municípios.

Além disso, os gestores de política pública, grandes empresários e boa parte dos cientistas ignoram o saber tradicional, mas é exatamente esse conhecimento que salva vidas no interior da região, e, baseando-se nele, muitos laboratórios desenvolvem suas pesquisas sobre novos medicamentos e produtos (MARQUES, 2019). 
Todavia, é necessário ressaltar que em nenhum plano de desenvolvimento ou empreendimento a população local foi chamada a opinar, mas "quem conhece a riqueza e os segredos da floresta e rios, sobrevive com menos de um salário mínimo mensal, resiste às diversas formas de violência, produz num solo frágil e quase sem nenhum apoio público, certamente tem muito a dizer" (MARQUES, 2019, p. 283).

\section{Considerações finais}

A trajetória histórico-social da Amazônia é marcada por exploração e apropriação de seus recursos naturais, visando atender aos interesses do capital externo. O plano de integração da região amazônica a nível nacional e internacional deu-se, portanto, de forma atrasada e subalterna. Vale destacar que a presença do Estado foi efetiva, principalmente no que diz respeito às políticas de desenvolvimento implementadas na região.

Investimentos em infraestrutura, como a construção de portos e estradas, criação de rodovias, aeroportos, hidrelétricas, sistema de comunicação, entre outros, foram estratégias utilizadas pelo aparato estatal com o intuito de modernizar a Amazônia. Entretanto, tais políticas intensificaram as expressões da questão social na região, culminando, contraditoriamente, no crescimento da desigualdade social, impactos ambientais, poluição dos rios, desmatamento, conflitos, violência etc.

Ademais, é importante ressaltar que as comunidades ribeirinhas, bem como os povos amazônicos em geral, ficaram completamente à margem desse processo. A exclusão, marginalização e invisibilidade vivenciadas pelas sociedades amazônicas é histórica. Na atual conjuntura de ultraneoliberalismo e com o governo de extremadireita favorável ao agronegócio, ao latifúndio e à mineração, visando unicamente o lucro, os conflitos e as desigualdades sociais anteriormente existentes, sobretudo com relação aos povos amazônicos, intensificaramse, sendo estes, os conflitos por terras, assassinatos de lideranças indígenas e o aumento das queimadas na Amazônia considerados como uma verdadeira tragédia ambiental na atualidade, entre outras questões.

O modo de vida desses grupos sociais, especialmente as comunidades ribeirinhas, cujo cotidiano é diretamente influenciado pelos fluxos dos rios, vai na contramão do modelo de civilização globalizada. Entretanto, é preciso reconhecer que, com a expansão do capitalismo na região, essas sociedades sofreram transformações sociais, políticas, econômicas, culturais e territoriais.

Porém, também foram identificadas formas de luta e resistência nesse processo histórico: a proposta de criação da reserva de lagos feitas pelos pescadores do Médio Amazonas (região que inclui os municípios de Faro, Oriximiná, Juruti, Óbidos, Santarém, Alenquer e Monte Alegre), apresentada por Furtado (2009), e a existência de uma rede de solidariedade familiar entre as comunidades ribeirinhas (ARENZ, 2000). No entanto, esta não é uma característica típica da tradição de convivência na zona rural da Amazônia, mas sim uma maneira de resgatar a identidade e a dignidade cultural frente à dinâmica global capitalista que fragmenta a vida.

A Amazônia é heterogênea, plural, territorialmente vasta, socialmente diversa e politicamente complexa (CAMPOS, 2013). Por isso, ao incorporá-la ao plano nacional, sobretudo no âmbito das políticas públicas, é necessário pensá-la a partir de suas especificidades, caso contrário, agravam-se as desigualdades regionais historicamente existentes.

\section{Referências}

ARENZ, K. H. Filhos e filhas do beiradão: a formação sócio-histórica dos ribeirinhos da Amazônia. Santarém: Faculdades Integradas do Tapajós, 2000.

BARROSO, S. C. Comunidades ribeirinhas na Amazônia: a dinâmica sociopolítica para acesso a bens e serviços sociais. Manaus: EDUA, 2015.

CAMPOS, E. B. As sociedades Amazônicas e o SUAS. In: CAMPOS, E. B. (org.). Fator amazônico e a interface com o Sistema Único de Assistência Social. 1. ed. Belém: ICSA/UFPA, 2013. p. 31-51.

CASTRO, E. Urbanização, pluralidade e singularidades das cidades amazônicas. In: CASTRO, E. (org.). Cidades na Floresta. São Paulo: Annablume, 2008. p. 13-39.

CASTRO, E.; SANTOS, M. A. Belém de águas e de portos: ação do Estado e a modernização na superfície. In: CASTRO, E. (org.). Belém de águas e ilhas. Belém: CEJUP, 2006. p. 25-43. 
CHAVES, G. P.; FURTADO, L. G. Entre rios, furos e igarapés: o ambiente aquático no imaginário social dos ribeirinhos de uma sociedade Amazônica. Contribuciones a las Ciencias Sociales, Universidad de Málaga, p. 1-13, jun. 2017. Disponível em: https:// www.eumed.net/rev/cccss/2017/02/index.htm. Acesso em: 25 set. 2018.

CHAVES, M. do P. S. R. Uma Experiência de Pesquisa-ação para Gestão Comunitária de Tecnologias Apropriadas na Amazônia: o estudo de caso do assentamento de Reforma Agrária Iporá. 2001. Tese (Doutorado em Política Científica e Tecnológica) - Programa de Pós-Graduação em Política Científica e Tecnológica, Instituto de Geociências. UNICAMP/CIRED, Campinas, SP, 2001. Disponível em: http://www.repositorio.unicamp.br/handle/REPOSIP/287073. Acesso em: 04 mar. 2018.

DIEGUES, A. C. O mito moderno da natureza intocada. 2. ed. São Paulo, SP: Hucitec, Nupaub/USP, 2008.

FERNANDES, J. S. N. Política de Assistência Social na Amazônia: problematizando o acesso das famílias ribeiinhas da Ilha das Onças, Barcarena/PA. 2020. Dissertação (Mestrado em Serviço Social) - Programa de Pós-Graduação em Serviço Social, Centro Socioeconômico, Universidade Federal de Santa Catarina, Florianópolis, 2020.

FRAXE, T. de J. P. Cultura cabocla-ribeirinha: mitos, lendas e transculturalidade. São Paulo: Annablume, 2004.

FURTADO, L. G. Comunidades tradicionais: sobrevivência e preservação ambiental. In: D’INCÃO, M. A.; SILVEIRA, I. M. da. (org.). A Amazônia e a crise da modernização. Belém, PA: ICSA-UFPA, 2009. p. 65-72.

FURTADO, L. G.; MANESCHY, M. C. Gens de mer et contraentes sociales: les pêcheurs côtiers de l'état du Pará, nord du Brésil. In: COLLOQUE NATIONAL ET INTERNATIONAL - ENTRE TERRE ET MER - SOCIÉTES LITTORALES ET PLURIACTIVITÉS XV-XX SIÈCLES. Lorient, França: 2002.

GOMES, V. L. B. Trabalho e desenvolvimento na Amazônia: notas para a reflexão no Estado do Pará. In: GOMES, V. L. B.; VIEIRA, A. C. de S.; NASCIMENTO, M. A. C. (org.). O avesso dos direitos: Amazônia e Nordeste em questão. Recife: UFPE, 2012. p. 145-175. HURTIENNE, T. O que significa a Amazônia para a sociedade global? In: D’INCÃO, M. A.; SILVEIRA, I. M. da. (org.). A Amazônia e a crise da modernização. Belém, PA: ICSA-UFPA, 2009. p. 153-156.

IAMAMOTO, M. V. O Serviço Social na contemporaneidade: trabalho e formação profissional. 17. ed. São Paulo: Cortez, 2009.

LIRA, T. de M.; CHAVES, M. do P. S. R. Comunidades Ribeirinhas na Amazônia: organização sociocultural e política. Interações. Campo Grande, MS, v. 17, n. 1, p. 66-76, jan./mar. 2016.

MAGALHÃES FILHO, F. Grandes projetos ou grande projeto? In: COSTA, J. M. M da. (Coord.). Os grandes projetos da Amazônia: impactos e perspectivas. Belém: NAEA/UFPA, 1987. (Cadernos NAEA, n. 9). p. 17-26.

MAGALHÃES, S. B.; CUNHA, M. C. da (org.). A expulsão de ribeirinhos em Belo Monte: relatório da SBPC. São Paulo: SBPC, 2017. MARQUES, G. de S. Amazônia: riqueza, degradação e saque. São Paulo: Expressão Popular, 2019.

MASCARO, A.L. Estado e forma política. São Paulo: Boitempo, 2013.

NETO, F. R.; FURTADO, L. G. A ribeirinidade amazônica: algumas reflexões. Cadernos de Campo, São Paulo, n. 24, p. 158-182, 2015. Disponível em: http://www.revistas.usp.br/cadernosdecampo/article/view/97408. Acesso em: 25 set. 2018.

NODA, S. et al. Utilização e apropriação das terras por agricultura familiar amazonense de várzea. In: DIEGUES, C. A.; MOREIRA, A. de C. C. (org.). Espaços e recursos naturais de uso comum. São Paulo: Núcleo de apoio à pesquisa sobre populações humanas e áreas úmidas brasileiras, USP, 2001.

POJO, E. C. et al. As águas e os Ribeirinhos: beirando sua cultura e margeando seus saberes. Revista Interdisciplinar da Divisão de Pesquisa e Pós-Graduação, Abaetetuba, v. 8, n. 11, p. 176-198, ago. 2014.

SÁ, M. E. E. R. de; NASCIMENTO, N. do S. F. Acumulação de capital e cidades na Amazônia: produção de riquezas e negação de direitos sociais. In: GOMES, V. L. B. et al. O avesso dos direitos: Amazônia e Nordeste em questão. Recife: UFPE, 2012. p. 201-224. SANTOS, M. O dinheiro e o território. In: SANTOS, M.; BECKER, B. (org.). Território, territórios: ensaios sobre o ordenamento territorial. 3. ed. Rio de Janeiro: Lamparina, 2007. p. 13-21.

SANTOS, M. O retorno do território. Debates, Buenos Aires, CLACSO, ano 6, n. 16, p. 251-261, jan. 2005. Disponível em: http:// bibliotecavirtual.clacso.org.ar/ar/libros/osal/osal16/D16Santos.pdf. Acesso em: 08 jan. 2020.

SANTOS, M. Por uma outra globalização. 6. ed. Rio de Janeiro: Editora Record, 2001.

SANTOS, M.; SILVEIRA, M. L. O Brasil: território e sociedade no início do século XXI. 9. ed. Rio de Janeiro: Editora Record, 2006. TEIXEIRA, J. B. A Amazônia e a interface com o SUAS. In: CAMPOS, Edval Bernardino (org.). Fator amazônico e a interface com o Sistema Único de Assistência Social. 1². Ed. Belém: ICSA/UFPA, 2013. P. 12-29.

TEIXEIRA, J. B. Meio Ambiente Amazônia e Serviço Social. Revista em Pauta da Faculdade de Serviço Social da Universidade do Estado do Rio de Janeiro, n. 21, p.141-152, UERJ, 2008. Disponível em: https://www.e-publicacoes.uerj.br/index.php/revistaempauta/ article/view/94/86. Acesso em: 29 mar. 2020.

WAGLEY, C. Uma comunidade amazônica: estudos do homem nos trópicos. Tradução de Clotilde da Silva Costa. São Paulo: Companhia Editorial Nacional, 1957. v. 290. (Série Biblioteca Pedagógica Brasileira Brasiliana, 5). 


\section{Joyce Sampaio Neves Fernandes}

joyce.sneves@gmail.com

Mestrado em Serviço Social pela Universidade Federal de Santa Catarina (UFSC/SC)

Doutoranda do Programa de Pós-Graduação em Serviço Social da Universidade Federal de Santa Catarina (PPGSS/UFSC)

\section{Liliane Moser}

liliane.moser@ufsc.br

Doutorado em Serviço Social pela Pontifícia Universidade Católica de São Paulo (PUC/SP)

Professora do Departamento de Serviço Social da Universidade Federal de Santa Catarina (UFSC)

\section{UFSC}

Campus Universitário João David Ferreira Lima - Trindade

Florianópolis - SC - Brasil

CEP: 88040-900

\section{Agradecimentos}

Não se aplica.

Agência financiadora

Não se aplica.

Contribuições das autoras

Artigo fruto de pesquisa bibliográfica realizada para a

dissertação de mestrado apresentada ao Programa de

Pós-Graduação em Serviço Social da UFSC, sob orientação da profa. Liliane Moser. O artigo foi elaborado com a colaboração das duas pesquisadoras.

Aprovação por Comitê de Ética

Não se aplica.

Consentimento para publicação

Consentimento das autoras.

Conflito de interesses

Não há conflito de interesses. 